\title{
Comparison of the MT Surgical Articulator to the Erickson Platform Method for the Execution of Model Surgery
}

\author{
Alexandre Laguna Terreri ${ }^{1}$, Ana Celia Faria*2 and Francisco Veríssimo de Mello Filho ${ }^{3}$ \\ ${ }^{1}$ Faculty of Medicine of Ribeirão Preto, University of São Paulo, Brazil \\ ${ }^{2}$ Department of Ophthalmology, University of São Paulo, Brazil \\ ${ }^{3}$ Department of Ophthalmology, University of São Paulo, Brazil \\ Received: 眥: October 06, 2018; Published: 䀺: October 16, 2018 \\ *Corresponding author: Ana Célia Faria, Department of Ophthalmology, Otorhinolaryngology and Head and Neck Surgery, Faculty of \\ Medicine of Ribeirão Preto, University of São Paulo - USP, venida Bandeirantes s/n, Ribeirão Preto 14049-900, SP, Brazil
}

Abstract

Objective: To test the use of the MT surgical articulator manufactured by Bio art, a company located in São Carlos, SP, Brazil, as an efficient and reliable method for model surgery and to compare the values obtained to those obtained with the Erickson platform.

Material and Methods: Model surgeries were performed using the Erickson platform and the MT surgical articulator and surgical guides were obtained with the following types of jaw movement: advancement of $5.0 \mathrm{~mm}$, posterior intrusion of $5.0 \mathrm{~mm}$, total intrusion of $5.0 \mathrm{~mm}$, left unilateral intrusion of $5.0 \mathrm{~mm}$, left laterality of $5.0 \mathrm{~mm}$, and left rotation of $5.0 \mathrm{~mm}$. The guides were measured using two Erickson platforms, one of them modified with the adaptation of a tip to the caliper. Lin's coefficient was used to determine the degree of concordance between the two pairs of measurements.

Results: The Lin coefficient obtained in the comparison of the measurements of the guides constructed on the Erickson platform to those obtained with the MT surgical articulator was 0.99721, with the maximum degree of concordance being 1.

Conclusion: There was no statistically significant difference between the measurements of the guides obtained on the Erickson platform and on the MT surgical articulator, a result that validates the use of the MT surgical articulator.

Keywords: Model Surgery; Surgical Dental Articulator; Surgical Guide

\section{Introduction}

Orthognathic surgery is a procedure of a medical/hospital nature consisting of various stages. One of them is model surgery whose objective is to obtain a surgical guide. The surgical guide provides to the surgeon the new position that the bone segment must occupy in the three-dimensional geometric space. Model surgery for obtaining the surgical guide can be performed in the semi-adjustable articulator [1] or on the Erickson platform (EP), [2] the latter being the method traditionally used more frequently for model surgery and considered to be the gold standard. Separate modifications of the structure of the semi-adjustable articulator have been suggested in order to facilitate the execution of model surgery with this device [3-5]. From this same perspective, surgical articulators have been devised for the specific execution of model surgeries [6-12]. However, no studies have compared the results obtained with these articulators to those obtained with the gold standard method.

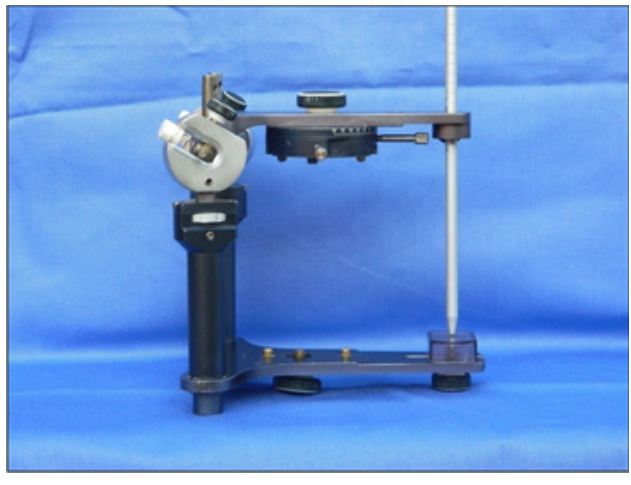

Figure 1: MT surgical articulator.

The MT surgical articulator (MTSA) manufactured by Bio-Art (Figure 1), a company located in São Carlos, SP, Brazil, consists of a 
platform fixed to the upper frame which permits the movement of the upper model in the anteroposterior, lateromedial and rotation direction and of a mechanism in the posterior rods that, together with the incisal pin, permits vertical adjustment. The objective of the present study was to determine whether the MTSA can be used as an efficient and reliable method for model surgery [13]. This was a comparative prospective double-blind study comparing the values obtained with the MTSA to those obtained with the EP.

\section{Material and Methods}

A pair of Rocky Mountain acrylic models was mounted on the MTSA in Angle class I normal occlusion. The incisal pin of the articulator, as well as the posterior rods, were adjusted to 5.0 $\mathrm{mm}$, creating a space between the models of the upper and lower dental arches [14]. Optosil heavy bodied silicone was manipulated and placed on one of the arches. By closing the articulator, the indentation of the arches was recorded on the silicone, producing the standard guide (SG).

\section{Surgical Guides Obtained with the MT Surgical Articulator}

Starting from the above occlusal position, some disocclusions were performed in the MTSA with jaw movements, simulating model surgeries by means of adjustments of the adjustable platform, of the mechanism of the posterior rods and of the incisal pin. Six types of jaw movement were produced in the following directions with $5.0 \mathrm{~mm}$ of movement increment: posteroanterior (advancement), posterior intrusion, total intrusion, unilateral left intrusion, left laterality, and right rotation. A guide was prepared for each of these disocclusions in the same way as described for SG production.

\section{Surgical Guides Obtained with the Erickson Platform}

The upper Rocky Mountain model was duplicated, providing six type IV plaster models. Using as reference the SG coupled to the lower Rocky Mountain model fixed in the lower frame of the articulator, each of these models was positioned by fixing it with type I plaster in the respective mounting plate of the upper frame of the articulator. The six plaster models were used for model surgery in the EP performed in the traditional manner, with the same six types of maxillary movement being produced as done with the MTSA, and with the surgical guides being obtained as described earlier.

\section{Guide Measurements}

The following reference dental points were marked and measured on the guides: apex of the mesiovestibular cusp of the first left upper molar; apex of the mesiovestibular cusp of the first right upper molar; apex of the cingulum of the incisal surface of the upper central incisor close to the dental midline. For the determination of guide measurements on a three-dimensional geometric space, the points were measured on three planes, i.e., vertical, horizontal and transverse, using two EP. The first had a tip adapted to the caliper for measurement on the vertical plane. The lower Rocky Mountain model was mounted on the base of the EP and the guides were positioned one at a time, perfectly fitting into the lower model. The first EP was used for measurements on the vertical plane and the second for measurements on the horizontal and transverse plane.

\section{Statistical Analysis}

The Lin coefficient was used [15] a method developed for the validation of measurements made with new instruments by comparing them to those obtained with well-established methods (gold standard). This coefficient is also used to determine the concordance between two pairs of measurements of the same samples at different times. The value of the concordance coefficient can vary from -1 to 1 , with 1 indicating maximum positive concordance [16]. Thus, we compared the guides obtained in the EP to those obtained in the MTSA, the guides obtained in the MTSA to the desired value and those of the EP guide to the desired values. The results were plotted graphically for visualization of the Lin coefficient.

\section{Results}

Model surgeries were performed in the EP and in the MTSA, with surgical guides being obtained with the following types of jaw movements: advancement of $5.0 \mathrm{~mm}$, posterior intrusion of $5.0 \mathrm{~mm}$, total intrusion of $5.0 \mathrm{~mm}$, left unilateral intrusion of $5.0 \mathrm{~mm}$, left laterality of $5.0 \mathrm{~mm}$, and left rotation of $5.0 \mathrm{~mm}$. The mean values obtained with the MTSA were compared to those obtained with the $\mathrm{EP}$ and to the desired values with $5.0 \mathrm{~mm}$ disocclusions. The mean measurements of the EP and MTSA surgical guides were calculated for each type of movement, as well as the mean difference between the value obtained and the desired value. The results are presented in Table 1. To visualize the precision of the EP method, we correlated the measurements of the guides obtained with the desired value (Figure 2). The Lin coefficient was 0.9985 . Similarly, to visualize the precision of the MTSA method, we correlated the measurements of the guides obtained with the desired value (Figure 3 ). The Lin coefficient was 0.9976 . Finally, we compared the measurements of the surgical guides obtained in the MTSA to those obtained in the guides of EP (Figure 4). The Lin co-efficient was 0.99721.

Table 1: Mean measurements ( $\mathrm{mm}$ ) obtained on the surgical guides of the Erickson platform and of the MT surgical articulator and mean desired value as the goal for each type of movement with $5.0 \mathrm{~mm}$ of increment.

\begin{tabular}{|c|c|c|c|c|c|}
\hline & \multicolumn{5}{|c|}{ Mean } \\
\hline $\begin{array}{c}\text { Type of } \\
\text { movement }\end{array}$ & $\begin{array}{c}\text { Desired } \\
\text { value }\end{array}$ & EP & MTSA & $\begin{array}{c}\text { Difference } \\
\text { (EP- } \\
\text { desired) }\end{array}$ & $\begin{array}{c}\text { Difference } \\
\text { (MTSA- } \\
\text { desired) }\end{array}$ \\
\hline A & 74.38 & 74.23 & 74.2 & -0.15 & -0.18 \\
\hline PI & 73.76 & 74.08 & 72.17 & 0.32375 & -1.58375 \\
\hline TI & 74.38 & 74.81 & 73.98 & 0.4225 & -0.4 \\
\hline LUI & 73.77 & 73.63 & 73.32 & -0.1375 & -0.4525 \\
\hline LL & 71.26 & 72.4 & 70.92 & 1.145 & -0.34125 \\
\hline LR & 71.88 & 71.98 & 71.74 & 0.0925 & -0.13875 \\
\hline
\end{tabular}

$\mathrm{EP}=$ Erickson Platform, MTSA $=$ MT Surgical Articulator, A = Advancement, PI = Posterior Intrusion, TI = Total Intrusion; LUI= Left Unilateral Intrusion, LL = Left Laterality, LR = Left Rotation. 


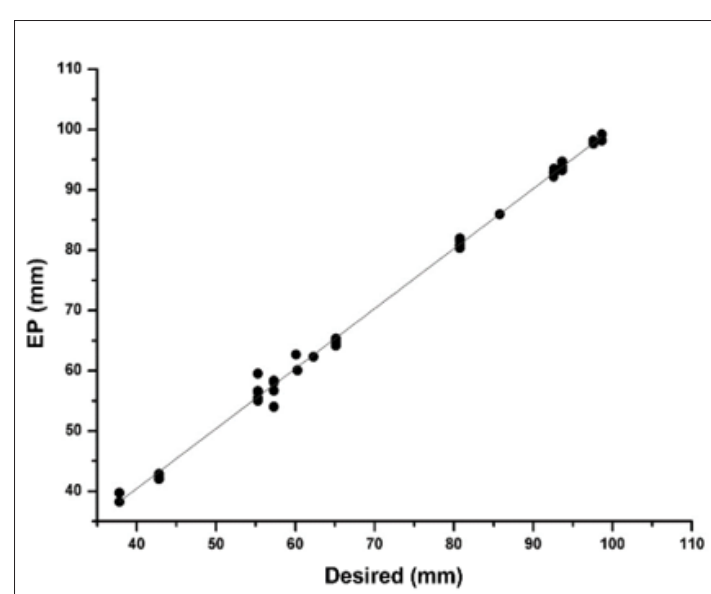

Figure 2: Correlation between the value of the measurements of the surgical guide obtained on the Erickson platform and the desired value. $y=-0.63+0.995 x$.

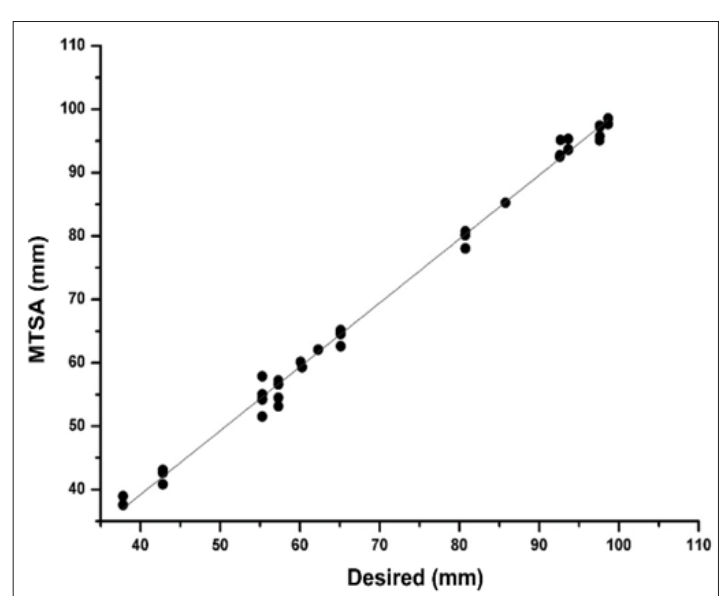

Figure 3: Correlation between the value of the measurements of the surgical guide obtained on the MT surgical articulator and the desired value. $y=-1.11+1.01 x$.

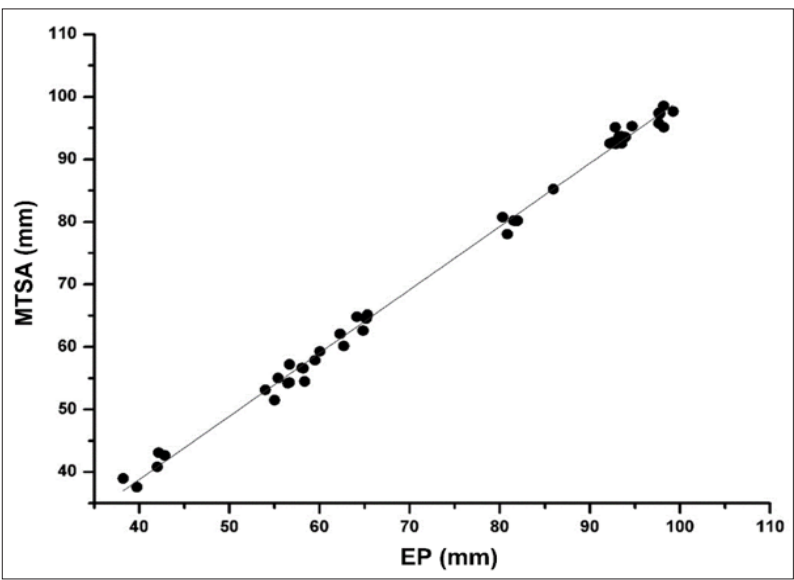

Figure 4: Correlation between the value of the measurements of the surgical guide obtained on the Erickson platform and the value of the measurements obtained on the MT surgical articulator with a $5.0 \mathrm{~mm}$ increment in the type of movement. $y=-1.65+1.012 x$.

\section{Discussion}

The measurements of the surgical guides obtained in the EP and the MTSA were compared. A correlation graph was obtained (Figure 4) and the Lin coefficient was 0.99721, thus showing that the guides were identical. Two other correlation graphs were also used to demonstrate the correlation between the measurements of the surgical guides obtained with the EP (Figure 2) and the MTSA (Figure 3) and the respective desired values. The Lin coefficient was 0.9985 for the EP and 0.9976 for the MTSA, confirming that the two methods are efficient and yield identical results. The EP is an excellent method which has been used for more than 30 years for model surgery with excellent results. The MTSA is a method whose results have been confirmed here to be the same as those obtained with EP, although they can be obtained in a less laborious, more rapid and mainly safer manner. The "just in time" visualization at the time the movement is performed permits corrections when necessary, thus avoiding unpleasant surprises at the time of in vivo surgery.

\section{Conclusion}

a) There was no statistically significant difference between the measurements of the guides obtained on the Erickson platform and on the MT surgical articulator.

b) This result validates the use of the MT surgical articulator.

\section{References}

1. Epker BN, Stella JP, Fish LC (1996) Dentofacial Deformities Integrated Orthodontic and Surgical Correction. $2^{\text {nd }}(E d n$.$) . 2: 1183$.

2. Erickson KL, inventor (1986) Measuring device for maxillofacial trial surgery. United States Patent US 4573917.

3. Bamber MA (1995) A modified articulator incisal pin for orthognathic surgery work-up. Br J Oral Maxillofac Surg 33(6): 396-397.

4. Hewitt R, Barnard D (1984) An articulator modification for the planning of maxillary osteotomies. Br J Oral Maxillofac Surg 22: 54-55.

5. Wong BW, inventor (1981) Adjustable occlusal plane table and method of use for orthognatic set up. United States Patent US 4624639.

6. Angelillo JC, Georgiade NG, Rabe, WC (1977) A prototype articulator for planning orthognatic and craniofacial surgery. J Oral Surgery 35(10): 847-849.

7. Monfredo JR, Roth RH, inventores (1983) Surgical dental articulator. United States Patent US 4391589.

8. Schwestka Polly R, inventor (1994) Articulator for cast surgery and method of use. United States Patent US 5281135.

9. Walker F, Ayoub AF, Moos KF, Berbenel J (2008) Face bow and articulator for planning orthognathic surgery: 2 articulators. Br J Oral Maxillofac Surg 46(7): 573-578.

10. Walker F, Ayoub AF, Moos KF, Berbenel J (2008) Face bow and articulator for planning orthognathic surgery: 1 face bow. Br J Oral Maxillofac Surg 46: 567-572.

11. Wong BW, inventor (1987) Surgical articulator apparatus and method. United States Patent US 4687442.

12. Wong BW (1990) Orthognathicocclusal relator system and technique. Orthodontic Review 4(2): 20-42.

13. Olszewski R, Reychler H (2004) Limitations of orthognathic model surgery: theoretical and practical implications. Rev Stomatol Chir Maxillofac 105(3): 165-169. 
14. Cottrell DA, Wolford LM (1994) Altered orthognathic surgical sequencing and a modified approach to model surgery. J Oral Maxillofac Surg 52(10): 1010-1020.

15. Lin KI (1989) A Concordance correlation coefficient to evaluete reproducibility. Biometrics 45(1): 255-268.

\section{ISSN: 2574-1241}

DOI: $10.26717 / B J S T R .2018 .10 .001900$

Ana Célia Faria. Biomed J Sci \& Tech Res

(C) $(7)$ This work is licensed under Creative

Submission Link: https://biomedres.us/submit-manuscript.php
16. Martelli Filho JA, Maltagliati LA, Trevisan F, Gil CTLA (2005) Novo método estatístico para análise da reprodutibilidade. R Dental Press Ortodon Ortop Facial 10: 122-129.

$\begin{array}{ll}\text { BIOMEDICAL } & \text { Assets of Publishing with us } \\ \text { RESEARCHES } & \text { - Global archiving of articles } \\ \text { - Immediate, unrestricted online access }\end{array}$

